\title{
Viewpoints
}

\section{Decoding Neurotransmitter Switching: The Road Forward}

\author{
${ }^{\circledR}$ Hui-quan Li, ${ }^{\circledR}$ Marta Pratelli, ${ }^{\circledR}$ Swetha Godavarthi, Stefania Zambetti, and ${ }^{\circledR}$ Nicholas C. Spitzer \\ Neurobiology Section, Division of Biological Sciences, Center for Neural Circuits and Behavior, Kavli Institute for Brain and Mind, University of \\ California, San Diego, La Jolla, California 92093-0115
}

Neurotransmitter switching is a form of brain plasticity in which an environmental stimulus causes neurons to replace one neurotransmitter with another, often resulting in changes in behavior. This raises the possibility of applying a specific environmental stimulus to induce a switch that can enhance a desirable behavior or ameliorate symptoms of a specific pathology. For example, a stimulus inducing an increase in the number of neurons expressing dopamine could treat Parkinson's disease, or one affecting the number expressing serotonin could alleviate depression. This may already be producing successful treatment outcomes without our knowing that transmitter switching is involved, with improvement of motor function through physical activity and cure of seasonal depression with phototherapy. This review presents prospects for future investigation of neurotransmitter switching, considering opportunities and challenges for future research and describing how the investigation of transmitter switching is likely to evolve with new tools, thus reshaping our understanding of both normal brain function and mental illness.

\section{Introduction}

Synaptic plasticity, defined as the activity-dependent modification of synaptic transmission, consists of a group of phenomena through which the neural activity generated by experience modifies neural circuit function, thereby influencing behavior. Classical forms of synaptic plasticity involve changes in synaptic strength (change in quantal content, quantal size, and/or postsynaptic receptors), synapse number (synaptogenesis or synaptic pruning), and electrical excitability (altered postsynaptic membrane properties; Citri and Malenka, 2008). Neurotransmitter switching is a newly recognized form of plasticity that involves the loss of one neurotransmitter and the gain of another in the same neuron (Borodinsky et al., 2004; Dulcis et al., 2013; Guemez-Gamboa et al., 2014; Li and Spitzer, 2020), typically in response to sustained stimulation for hours to days.

At the molecular level, transmitter switching is regulated by cytokines (Yamamori et al., 1989), growth factors (Yang et al., 2002; Marek et al., 2010; Guemez-Gamboa et al., 2014), transcription factors (Demarque and Spitzer, 2010), microRNAs (miRNAs; Dulcis et al., 2017), and epigenetic mechanisms (Pritchard et al., 2020), and it is accompanied by matching changes in postsynaptic neurotransmitter receptors that enable continued function of the synapse (Borodinsky and Spitzer, 2007; Dulcis and Spitzer, 2008; Dulcis et al., 2013; Bertuzzi et al., 2018). In the majority of cases, switching changes the synapse from excitatory to inhibitory or vice versa (Spitzer, 2017) and it is causally linked to changes in behavior (Li and Spitzer, 2020). In combination with Hebbian and homeostatic plasticity, switching forms a triumvirate of forms of plasticity that enables changes in synaptic strength (Penn and Shatz, 1999), synaptic scaling (Turrigiano, 2008) and reversal of

Correspondence should be addressed to Nicholas C. Spitzer at nspitzer@ucsd.edu.

https://doi.org/10.1523/JNEUROSCI.0005-20.2020

Copyright $\odot 2020$ the authors synaptic sign (Spitzer, 2017). Transmitter switching has been studied in many species, including Caenorhabditis elegans (Pocock and Hobert, 2010; Serrano-Saiz et al., 2013), zebrafish (Bertuzzi et al., 2018), Xenopus (Borodinsky et al., 2004; Dulcis and Spitzer, 2008; Demarque and Spitzer, 2010; Dulcis et al., 2017), and rats and mice (Patterson and Chun, 1977; Schotzinger and Landis, 1988; Dulcis et al., 2013; Meng et al., 2018; Li and Spitzer, 2019, 2020; Romoli et al., 2019; Prakash et al., 2020).

Changes in transmitter expression and excitation-inhibition imbalance have been implicated in neurologic and psychiatric disorders (Lopatina et al., 2019; Sohal and Rubenstein, 2019). Interestingly, transmitter switching has been associated with behavioral alterations in several psychiatric illnesses, including anxiety and depression (Dulcis et al., 2013), drug abuse (Romoli et al., 2019; Prakash et al., 2020, Pratelli and Spitzer, 2019), autism spectrum disorder (Godavarthi and Spitzer, 2017), and post-traumatic stress disorder (Li and Spitzer, 2019). A deeper understanding of this form of neuroplasticity may enable future manipulations of transmitter switching in human subjects for therapeutic purposes. Indeed, some transmitter switches yield beneficial effects ( $\mathrm{Li}$ and Spitzer, 2020), suggesting the possibility of harnessing transmitter switching as a restorative treatment. However, obtaining a beneficial or therapeutic effect by voluntary induction of transmitter switching through the application of specific stimuli requires substantial research. The time and resource intensiveness of methods used currently have prevented analysis of transmitter switching at whole-brain scale and have limited the number of environmental stimuli that have been investigated. To exploit the full potential of neurotransmitter switching, tools enabling rapid, automatic, and brain-wide screening of the incidence transmitter switching are needed.

In this article, we propose new tools to aid in efficient and high-throughput study of transmitter switching, discuss the gaps in our understanding, and identify new lines of investigation. 
Finally, we discuss how the understanding gained from studying switching and its behavioral impact in animal models can inform treatment strategies for neurologic and psychiatric disorders in humans.

\section{Available tools}

Tools are currently available that can accelerate progress in better understanding transmitter switching by substantially increasing the efficiency of analysis. One useful strategy involves combining labeling of switching cells with genetically encoded fluorescent reporters, whole-brain tissue clarification, high-resolution wholebrain scanning, and use of algorithms for automatic cell quantification. These tools are already widely used in research, although some optimization may be needed for specific applications. Another valuable approach entails live imaging of individual neurons in situ, using either implanted minicams or in vivo two-photon imaging of the brains of transgenic animals expressing fluorescent protein reporters. Such studies will enable analysis of the kinetics of switching and the temporal order of transmitter loss and gain at the level of single neurons. A third important direction involves the study of synaptic physiology. Anatomical studies of transmitter switching, identifying newly expressed transmitters and their matching receptors, have shown that changes in presynaptic transmitter expression are accompanied by changes in postsynaptic receptor expression (Borodinsky and Spitzer, 2007; Dulcis and Spitzer, 2008; Dulcis et al., 2013; Bertuzzi et al., 2018). Demonstrations of the causal link between transmitter switching and changes in behavior provide support for the integrity of synapse function (Li and Spitzer, 2020). Because the presynaptic changes generally appear to involve a change from an excitatory to an inhibitory transmitter or vice versa, there is urgency to making presynaptic and postsynaptic recordings before and after switching to confirm the change in sign of the synaptic signal.

\section{Tools to develop}

\section{Genetic mouse models}

Current genetic labeling approaches often use mouse, fish, fly, or worm lines expressing the Cre or Flp recombinase under the control of cell-specific promoters that drive the expression of Credependent or Flp-dependent reporters (Sauer, 1998; Bouabe and Okkenhaug, 2013). Here we consider two examples of refinements of this basic strategy, focusing on the switch involving glutamate and GABA (Fig. 1A), since these are the most abundant transmitters in the brain.

One approach to genetically label switching neurons uses a mouse that carries (1) a tamoxifen-inducible recombinase CreER $^{\mathrm{T}}$ (Metzger and Chambon, 2001) under the control of the promoter of vGluT1 (vesicular glutamate transporter 1) specifically expressed in glutamatergic neurons; (2) an Flp recombinase under control of the promoter of GAD1 (glutamate decarboxylase 1) specifically expressed in GABAergic neurons; (3) a dual Credependent and Flp-dependent reporter (e.g., far red katushka photoprotein; Jensen and Dymecki, 2014); (4) a GFP under control of the promoter of GAD1 (Tamamaki et al., 2003); and (5) a nuclear localized H2B-mCherry under control of the promoter of vGluT1 (Fig. 1B). With this mouse, after the induction of $\mathrm{CreER}^{\mathrm{T}}$ with tamoxifen before the exposure to a switching-inducing stimulus, only neurons coexpressing GAD1 and vGluT1 express katushka. After exposure to the stimulus, the number of katushka-positive neurons will increase to include switching neurons. The presence of the $\mathrm{H} 2 \mathrm{~B}-\mathrm{mCh}$-rry and the GFP reporters, which label, respectively, neurons expressing vGluT1 or GAD1 at the time of analysis, will distinguish switching neurons from coexpressing ones. Neurons that switch from glutamate to GABA will coexpress katushka and GFP, but not mCherry. Similarly, if tamoxifen is administered during the exposure of the inducing stimulus, coexpression of katushka and H2B-mCherry will identify neurons that switch from GABA to glutamate. This strategy will be useful for single-cell sorting followed by RNA sequencing (RNAseq; Okaty et al., 2015) or multimodal profiling (Stuart and Satija, 2019), and particularly for whole-brain screening for transmitter switching.

It is worth mentioning that a switch may involve a change in the levels of transmitters rather than complete replacement ( $\mathrm{Li}$ and Spitzer, 2020). If so, a primarily glutamatergic neuron with a low level of GAD1 expression could express katushka before the switch when low levels of dual Cre/Flp expression are sufficient to induce the expression of the dual reporter. In such cases, switching neurons could not be distinguished by katushka expression alone. However, a switch would be identified when the numbers of neurons doubly positive for katushka and mCherry or katushka and GFP differ between the experimental mice exposed to the switch-inducing stimulus and control mice that were not exposed to the stimulus.

An alternative approach to genetically labeling a switch from glutamate to GABA uses a mouse expressing (1) a $\mathrm{CreER}^{\mathrm{T}}$ tamoxifen-inducible recombinase under control of the vGluT1 promoter; (2) a Cre-dependent H2B-katushka reporter; (3) a GFP under control of the promoter of GAD1; and (4) a nuclear localized H2B-mCherry under control of the promoter of vGluT1. Tamoxifen induction of $\mathrm{CreER}^{\mathrm{T}}$ recombinase activity just before exposing the mouse to the environmental stimulus under investigation will permanently mark glutamatergic neurons with katushka. After stimulus exposure, it will be possible to immediately distinguish which glutamatergic neurons have lost glutamate and gained expression of GABA, as they will coexpress katushka and GFP but not vGluT1-driven H2B-mCherry. Neurons that have not switched from glutamate to GABA will continue to express katushka and $\mathrm{H} 2 \mathrm{~B}$-mCherry, and coexpression of all three reporters will identify glutamatergic neurons coexpressing both GAD1 and vGluT1 (Fig. 1C). This strategy, allowing permanent labeling of glutamatergic neurons and real-time visualization of changes in expression of GAD1 and vGluT1 through the expression of GFP and mCherry, respectively, would be particularly suitable for two-photon in vivo imaging (Katona et al., 2012) and for investigating the kinetics of switching.

Though generating and maintaining mice carrying five knockin (KI) alleles at the same time is difficult with conventional methods, the task is now significantly facilitated by CRISPR technology that allows the induction of multiple mutations at the same time, as well as the insertion of additional mutations into the genome of an already established KI mouse line (Burgio, 2018). These two different mouse models, despite sharing some similarities, possess specific features that make each of them more suitable for specific applications. For example, the mouse described in Figure $1 B$ has the advantage of allowing the detection of transmitter switching from glutamate to GABA as well as from GABA to glutamate, on adjustments in the experimental design, whereas the line described in Figure $1 C$ can be used to visualize only the glutamate-to-GABA switch. Another important advantage of the mouse line described in Figure $1 B$ is the quick and easy detection of brain regions in which switching occurs, which will show an increase in the number of katushka-positive cells. The 

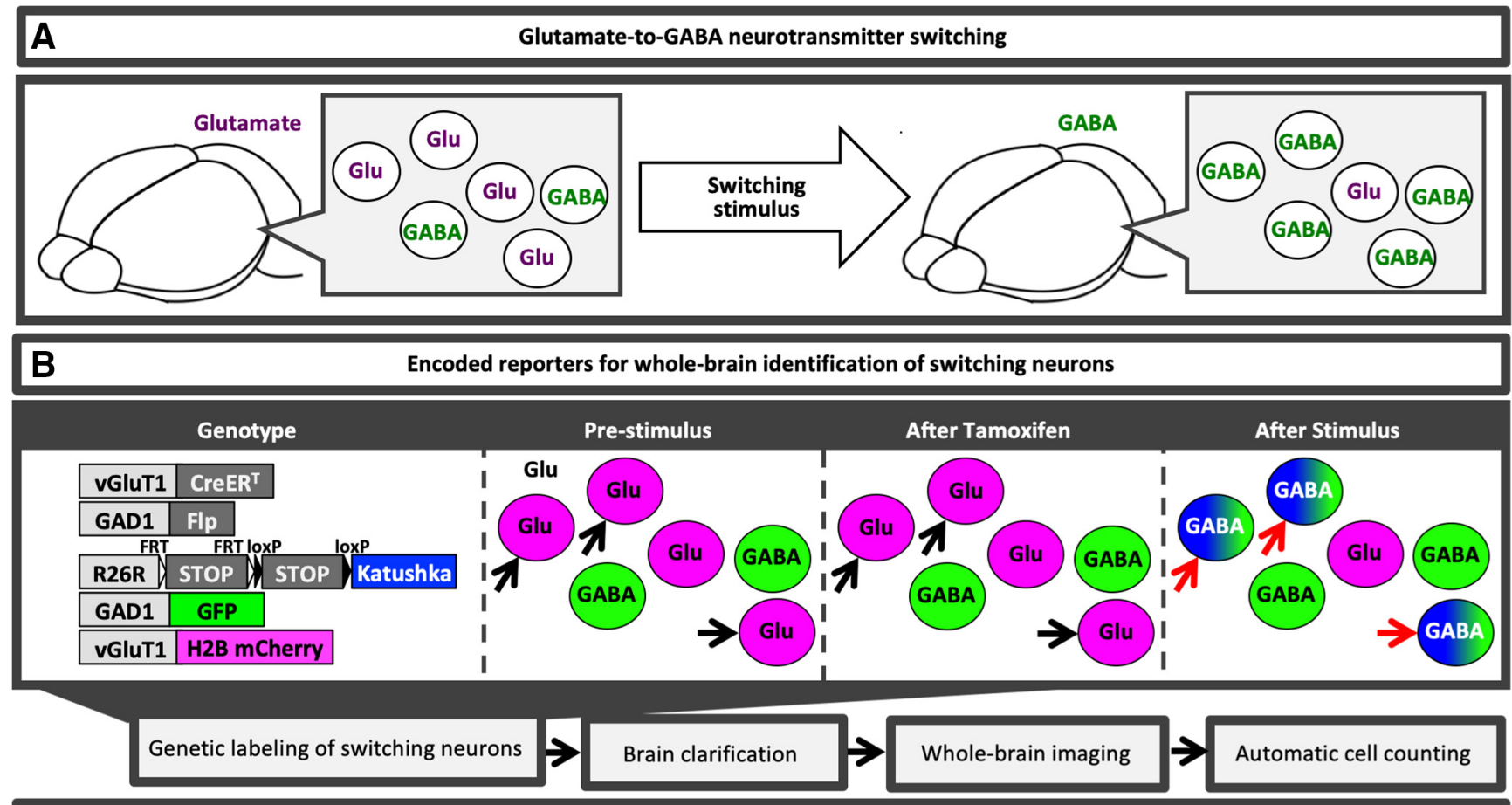

C Encoded reporters of transmitter switching dynamics in vivo

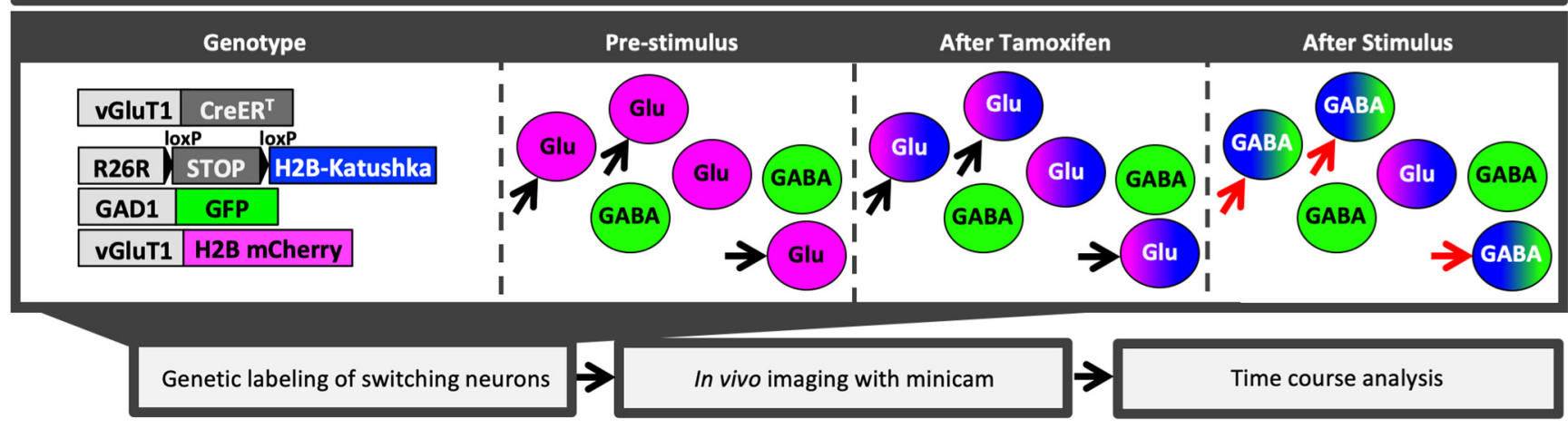

Figure 1. Genetic reporters of transmitter switching in the adult brain. $A$, Glutamate to GABA is the most frequently observed switch. $B$, $C$, Strategies for genetic labeling of switching neurons. Left to right, mouse genotype, fluorescent reporters expressed before stimulation, after activation of CreER recombinase by tamoxifen, and after switching has been induced. $\boldsymbol{B}$, This strategy will provide high-throughput brain-wide identification and quantification of transmitter switching. $\boldsymbol{C}$, This strategy will yield real-time information about the kinetics of switching in relation to stimulus activity.

presence of GFP and H2B-mCherry can then be evaluated to discriminate between GAD1/vGluT1 coexpressing neurons and switching cells with single-cell resolution. Instead, the mouse described in Figure 1C, by combining permanent labeling of glutamatergic neurons and dynamic visualization of vGluT1 and GAD1 expression, is more suited for in vivo imaging of the dynamics of transmitter switching than the model proposed in Figure $1 B$, in which a stable katushka label appears only after the switch has occurred. These and similar approaches will be useful in boosting the efficiency of the search for switching neurons by accelerating the process on a whole-brain scale and allowing in vivo imaging of transmitter switching.

While genetically driven reporters can be widely applied in rodents, their application in nonhuman primates has been challenging, making it difficult to expand research to these model systems. Recent development and use of genetic tools in monkeys and marmosets (Chen et al., 2016; Kang et al., 2019) make investigations of transmitter switching in these animals amenable for study in the near future.
High-throughput multicolor imaging methods

Brain-wide screening of transmitter switching in rodent brains will be facilitated by high-throughput multicolor imaging systems. Such large-scale imaging should be (1) automatic and fast to allow high-throughput screening, (2) at single-cell spatial resolution to enable identification of transmitter switching, and (3) dual-channel or triple-channel capable to distinguish one genetic marker from another (e.g., with GFP, mCherry, and katushka, as described above). A variety of cutting edge imaging technologies have recently been developed to meet these requirements. Light sheet imaging of the cleared brain enables high-speed optical sectioning to map labeled cells in reporter mouse brains (Dodt et al., 2007), and multiple clearing methods are currently available with different distinguishing features (Susaki et al., 2014; Tomer et al., 2014; Hama et al., 2015). Expansion microscopy methodology is an option to acquire higher-resolution images of cleared wholebrain tissues (Park et al., 2019). In addition, serial section imaging methods have been developed to achieve high spatial resolution without tissue clearance (Ragan et al., 2012; Seiriki et al., 2019). 
Although it takes longer ( $3 \mathrm{~d})$ to image a single mouse brain, the higher resolution that these methods can achieve allows $3 \mathrm{D}$ visualization of axonal projections from single neurons ( $\mathrm{Li}$ et al., 2010; Gong et al., 2016). Faster acquisition of 3D images can be achieved with block-face serial microscopy tomography (FAST), which uses the multipinhole imaging method by spinning-disk confocal microscopy (Seiriki et al., 2017). For screening transmitter switching, FAST seems a particularly appealing approach because it is less demanding in microscopy setup and data acquisition systems and achieves single-cell resolution without concerns for tissue shrinkage or expansion. These advanced imaging technologies provide opportunities for global screening of transmitter switching, although they are currently not available at many research institutions and are still expensive.

\section{Expanded positron emission tomography}

Positron emission tomography (PET) scanning has been used to evaluate levels of dopamine, serotonin, glutamate, GABA, and acetylcholine (ACh) transporters and receptors in the brain (Lancelot and Zimmer, 2010). Because transmitter transporters regulate transmitter levels and synaptic transmission (Liu et al., 1999), and transmitter receptors change to match changes in neurotransmitters (Borodinsky and Spitzer, 2007; Dulcis and Spitzer, 2008; Dulcis et al., 2013; Bertuzzi et al., 2018), this technology may be used to indirectly identify potential switching neurons noninvasively in human subjects (Alpert et al., 2003). PET scans of subjects with schizophrenia, mood disorders, or drug abuse have provided important insights into the pathophysiology, diagnosis, and prognosis of these conditions (Newberg et al., 2011). Radiotracers, now available for some but not all classes of transmitter transporters and receptors, may be used to identify transmitter switching (Rice et al., 2001; Heiss and Herholz, 2006). The development of new tracers will broaden the application of this preclinical approach.

\section{Cellular analysis of neurotransmitter switching}

Where does transmitter switching occur?

Whether all neurons are capable of switching or if this is restricted to particular classes of neurons is an open question. The propensity for plasticity changes during development and the threshold depends on both the type of neuron and its function in its circuitry (Kolb and Gibb, 2011). Similar features can be foreseen for transmitter switching. It is likely that some neurons switch transmitters easily while others have a high threshold for switching. High-throughput single-cell RNA sequencing (Lake et al., 2016; Rosenberg et al., 2018) may be a useful approach to identify neurons that are capable of switching transmitters.

Transmitter switching in the cell body is accompanied by switching in axon terminals in the adult brain (Dulcis et al., 2013) and the developing brain (Nabekura et al., 2004; Dulcis and Spitzer, 2008). The observation that neurons can coexpress two transmitters and release them selectively from different presynaptic terminals (Mentis et al., 2005; Nishimaru et al., 2005) raises the possibility that in some cases switching can occur at the level of nerve terminals and synapses without a change in the expression of transmitters in the neuronal cell body. Novel and more comprehensive screening strategies will be needed to detect such changes.

\section{Which transmitter pairs switch in single neurons?}

Learning which transmitters can be expressed or suppressed in specific neurons and identifying the switch partners with which they are paired is an intriguing problem. Excitatory transmitters generally have inhibitory transmitters as switch partners and vice versa (Spitzer, 2017), although the ultimate determinants of synaptic sign are the receptors. Classical low-molecular-weight transmitters have been observed to switch with other classical transmitters (Grant et al., 1995; Godavarthi and Spitzer, 2017; Li and Spitzer, 2019, 2020; Pratelli and Spitzer, 2019; Romoli et al., 2019; Prakash et al., 2020) and with peptide transmitters (Dulcis et al., 2013; Zambetti et al., 2017). There does not presently seem to be a reason to anticipate that members of any class of transmitters are forbidden switch partners.

It seems unlikely that individual neurons are capable of expressing all of the $\sim 100$ known or suggested neurotransmitters. What are the limitations to the number and variety of transmitters that can be expressed by a single neuron? One may imagine that particular neurons have the potential to express a specific subset of transmitters when required by environmental conditions. The question then becomes how is transmitter switching achieved? Transcriptional dependence has been observed and may be a common mechanism (Dulcis et al., 2013; Meng et al., 2018; Li and Spitzer, 2020). Nonetheless, transcripts of neurotransmitter synthetic enzymes have also been observed in the absence of the detection of the enzymes themselves (Meng et al., 2018), suggesting that regulation at translational or post-translational levels can be involved.

\section{How rapidly do transmitters switch?}

Transmitter switching generally requires prolonged stimulation. It has been observed after as little as a few hours of sustained stimulation in the developing Xenopus CNS (Dulcis and Spitzer, 2008) or as long as a period of days in the adult rodent brain (Dulcis et al., 2013; Li and Spitzer, 2020). Direct in vivo observation of transmitter switching combining minicam or two-photon microscopy with genetically encoded reporters will likely enable earlier detection. As more information about the regulatory signal transduction cascades becomes available, it may be possible to detect even earlier signs of switching. Change in expression of the vesicular transporter in presynaptic terminals occurs consistently with the transmitter switch in the cell bodies ( $\mathrm{Li}$ and Spitzer, 2020). However, whether the switch in presynaptic terminals occurs at the same rate as in cell bodies remains an open question. The gain and loss of transmitters appear to occur in close temporal order, but whether one usually precedes the other is currently unknown.

\section{Is transmitter switching reversible?}

Mice voluntarily running on a running wheel for $\geq 1$ week undergo changes in behavior associated with transmitter switching in the pedunculopontine nucleus (PPN) and in the hilus of the dentate gyrus (DG). The switches in the PPN (from ACh to GABA) and in the hilus (from NPY to glutamate) reverse spontaneously after 1 week of rest (Zambetti et al., 2017; Li and Spitzer, 2020). In contrast, the changes in behaviors persist. This raises the possibility that the primary transmitter switch induces secondary changes in downstream brain regions and potentially a secondary switch (Fig. 2), which in turn allows the behavioral alterations to persist.

\section{How does the capability for transmitter switching change with age?}

Brain plasticity is developmentally regulated, raising the possibility of specific time windows of plasticity during which the potential of a specific subset of neurons to undergo transmitter 


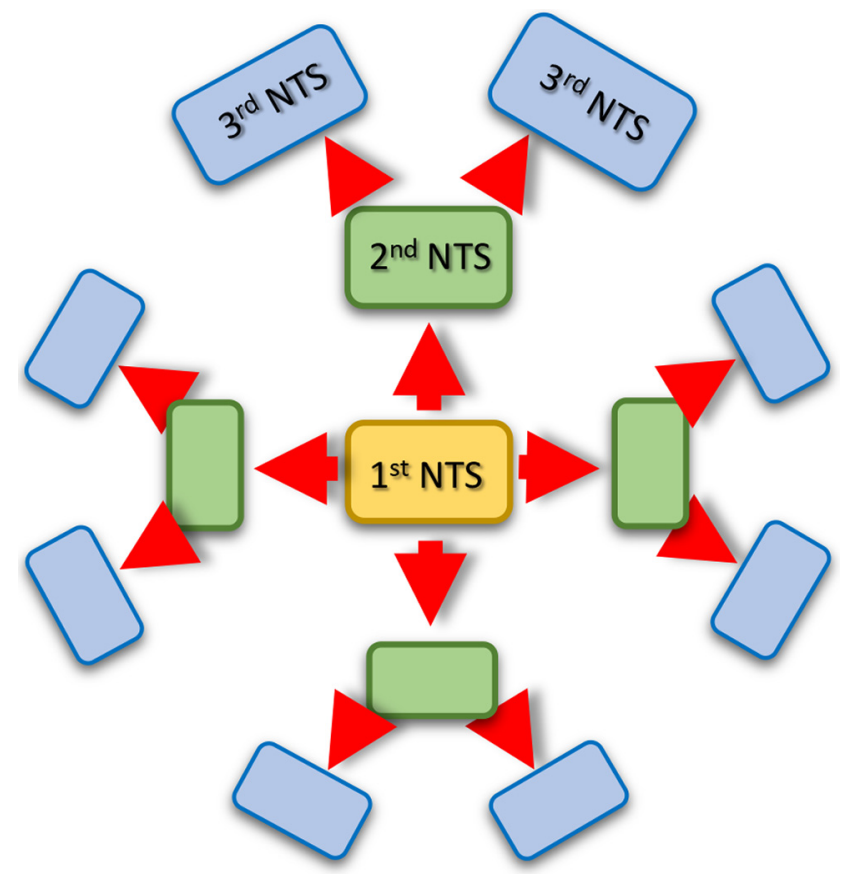

Figure 2. Cascades of transmitter switching. A stimulus triggers a primary transmitter switching event in one brain region (yellow rectangle), which then induces secondary switching (green rectangles) and even tertiary switching (blue rectangles). Prevention of transmitter switching at the primary level will prevent the consequent secondary and tertiary events.

switching is enhanced. Brain plasticity typically seems to decline with age. In rodents, the number of neurons generated in the subgranular zone of the dentate gyrus decreases with aging (Bizon et al., 2004; Enwere et al., 2004; Amrein et al., 2011). Long-term potentiation (LTP) and long-term depression are reduced with aging in rodents and humans (Barnes, 1979; Deupree et al., 1991; Norris et al., 1996; Dieguez and Barea-Rodriguez, 2004; Spriggs et al., 2017). A similar decline has been observed for transmitter switching, as photoperiod-induced dopamine-to-somatostatin switching in the hypothalamus is reduced in aged rats (Pritchard et al., 2020).

The development of brain circuitry and function arises out of complex interactions between genetic and environmental influences. However, describing the emergence of complex traits, such as mating behavior, language, or reading, during the lifetime of an animal has been a challenge for scientists. Charles Darwin elaborates in The Origin of Species how many complex traits evolved from earlier traits that served different functions. This "repurposing" or "exaptation" (Gould and Vrba, 1982) of existing traits can occur at the genetic level when one gene results in or influences more than one phenotype (pleiotropy). It can also occur at the circuit level when pre-existing circuits are co-opted for new functions (neural plasticity). Circuits that evolved and develop for basic function $\mathrm{X}$ are co-opted for a new function $\mathrm{Y}$ with maturation of the animal. Maturation can in turn comprise several factors such as age, sex, internal state, and learning. For example, in rodents, brain regions involved in olfaction are co-opted for courtship behaviors during sexual maturation (Hull and Dominguez, 2007), and in female rodents brain regions involved in sexual behavior are co-opted for postpartum maternal care (Pereira and Morrell, 2011). In humans, Broca's area and Wernicke's area, which serve as association and memory storage areas, are co-opted during maturation to serve as language areas (Cooper, 2006). The role of switching in exaptation has been unexplored.

\section{Molecular regulation of neurotransmitter switching}

What is the role of electrical activity in transmitter switching?

Sustained change in neuronal activity plays a critical role in the induction of switching, as shown by studies of the developing Xenopus nervous system (Spitzer, 2012) and the adult rodent brain (Meng et al., 2018; Li and Spitzer, 2020). In Xenopus, prolonged suppression of neuronal activity has been shown to cause transmitter switching (Borodinsky et al., 2004; Demarque and Spitzer, 2010). In rats, exposure to a long-day photoperiod induces switching from dopamine to somatostatin in a subset of neurons in the paraventricular hypothalamic nucleus (PaVN; Dulcis et al., 2013); this is associated with an increase in neuronal activity in this region. Suppressing this increase in activity specifically in dopaminergic PaVN neurons, through selective expression of inward rectifier potassium channels, is sufficient to suppress transmitter switching (Meng et al., 2018). Furthermore, suppressing the activity of glutamatergic neurons in the $\mathrm{PaVN}$ is sufficient to induce a decrease in the number of dopaminergic neurons that is similar to that observed after exposure to the long-day photoperiod. This evidence has been important to establish a causal relationship between neuronal activity and transmitter switching in the adult rodent brain and to demonstrate the feasibility of inducing switching through manipulation of neuronal activity in vivo.

It is now possible to implement novel experimental paradigms to manipulate neuronal firing in the adult rodent brain to investigate the forms of activity that modulate neurotransmitter identity. An important first step will be to image electrical activity in vivo using twophoton microscopy or implanted minicams and genetically encoded calcium or voltage sensors (Chen et al., 2013) expressed in neurons expected to undergo switching. Understanding the natural patterns of activity is important to determine the physiological parameter space before introducing experimental manipulations. Selective manipulation of neuronal activity will then be useful for dissecting the activity requirement for transmitter switching in vivo. To achieve this goal, optogenetic stimulation (Mahmoudi et al., 2017) or chemogenetic stimulation (Sternson and Roth, 2014) of neurons with channelrhodopsins (ChRs) or designer receptors exclusively activated by designer drugs (DREADDS) can be combined with the use of genetically encoded reporters (Fig. 1D) to artificially induce switching through activity manipulation.

To determine whether and in which neuronal populations switching is induced after optogenetic or chemogenetic stimulation, Cre-dependent or Cre-ON/Flp-ON doubly inducible viral vectors (Fenno et al., 2014) can be used to drive the expression of ChR or DREADDs in specific subgroups of neurons. With these tools, activity can be manipulated specifically in neurons that are expected to switch, only in their neighboring neurons, or in all neurons within a brain region. In addition, electrical activity can be manipulated even more selectively within a specific population of neurons using Cre-ON/Flp-ON doubly inducible viral vectors to observe the effects on both the targeted neurons and the neighboring cells. Such studies may identify the subgroups of neurons that undergo switching in response to sustained stimulation of large populations and may help to determine whether neuronal activity can drive transmitter switching through cell-autonomous or non-cell-autonomous mechanisms in the adult brain.

\section{What are the molecular mechanisms of transmitter switching?}

The molecular pathways that guide switching in the mammalian brain are another essential aspect to be investigated. Although 
transmitter switching is generally driven by sustained changes in neuronal activity, relatively little is known about the downstream molecular mediators. The importance of studying these mechanisms is clear, as understanding the signaling cascades may identify opportunities for clinical manipulation of this neuroplasticity. Indeed, given the obvious challenge of directly manipulating neurotransmitters in the human brain, specific molecular mediators of transmitter switching may be more druggable targets. If there were a generic molecular mechanism by which transmitter switching is regulated-perhaps a specific sustained elevation of intracellular calcium, activation of particular immediate early genes, or phosphorylation of a certain kinase-detecting its presence or absence would be straightforward. However, there is no basis at present to assume a single mechanism, and this question is outstanding.

One approach to initiate the study of molecular mechanisms of neurotransmitter switching in the adult brain is to take advantage of the knowledge obtained from studies of the developing brain. For example, it may be promising to test whether the brain-derived neurotrophic factor (BDNF), its TrkB receptor (Guemez-Gamboa et al., 2014), and/or specific miRNAs (Dulcis et al., 2017) also mediate transmitter switching in the adult brain.

Another approach to identifying molecular pathways that regulate transmitter switching in the adult is to use high-throughput screening methodologies such as RNAseq or single-cell transcriptomic profiling. RNAseq can use translating ribosome affinity purification (TRAP), with floxed TRAP mice crossed with specific Cre mouse lines to enable cell type-specific TRAP expression (Heiman et al., 2014; Nectow et al., 2017). Dissecting the tissue of a selected brain region in these mice immediately after delivering a switch-inducing stimulus, then extracting and sequencing the mRNA that is being actively translated, will enable screening for signaling molecules (e.g., transcription factors) that are either upregulated or downregulated. Changes in the levels of these molecules will identify potential signaling mediators of transmitter switching. This screening will provide the basis for further validation of the change and allow functional studies of the roles of these molecules in transmitter switching.

Alternatively, the use of appropriate transgenic mouse lines designed to specifically label switching neurons (Fig. 1) may allow single-cell sorting followed by transcriptomic analysis. Comparing the transcriptomes of cells that switch with those of cells that do not switch in response to a specific stimulus could illuminate the signal transduction cascades of this form of neuroplasticity. Additional information might be obtained by comparing the profiles of different subtypes of neurons that switch in response to different stimuli. Given that transmitter switching involves changes in the transcription of genes encoding transmitter synthetic enzymes (Dulcis et al., 2013; Li and Spitzer, 2020), learning the identity of the transcription factors that regulate the process and determining the way in which they interact combinatorially is of interest. Overall, studying the mechanism underlying switching will provide insight into the way this plasticity is achieved and may identify switching that can be manipulated for clinical benefit.

Epigenetic regulation is a strong candidate to play a role in transmitter switching. Neuronal activity is central to its induction and may drive gene expression through epigenetic mechanisms (He et al., 2011; Su et al., 2017). For example, epigenetic modifications like DNA methylation and histone acetylation regulate the ability of adult rat hypothalamic neurons to respecify their transmitter in response to changes in the length of photoperiod
(Pritchard et al., 2020). It will be of interest to learn how epigenetic regulation plays a role in other cases of transmitter switching.

\section{What is the relationship between transmitter switching and transmitter coexpression?}

Like transmitter switching, discovery of transmitter coexpression challenges the "one neuron, one neurotransmitter" dogma according to which synaptic transmission between two neurons occurs through the release of a single chemical transmitter. Coexpression and corelease of transmitters are now well documented throughout the mature mammalian brain (Tritsch et al., 2016). Switching occurs in neurons that coexpress other transmitters (Baker, 1990; Meng et al., 2018), as well as in neurons for which only a single transmitter has been identified. This raises the possibility that, at least in some circumstances, neurons expressing more than one transmitter are undergoing switching during which coexpression is an intermediate phase. If this is true, a snapshot of a neuron at any single time point would identify the presence of several transmitters, but this would be a dynamic rather than a permanent phenotype. Transient coexpression and corelease of transmitters have been observed early in postnatal development (Nabekura et al., 2004). If transmitter coexpression involves transmitter switching, the same neurons that express both GABA and glutamate under one condition, for example, may show sole expression of GABA or glutamate under other conditions. Expression of GABA, glutamate, or both would reflect the state of the neurons and not their identity. Coexpressing neurons could be considered as reserve pool neurons (Dulcis and Spitzer, 2012) with high capability of adjusting their transmitter identity in response to environmental requirements.

\section{Switching postsynaptic receptors}

What is the mechanism by which postsynaptic receptors change? The functional success of transmitter switching presumably depends on the change in identity of transmitter receptors expressed by the postsynaptic target cell in response to the gain or loss of transmitter in the presynaptic neuron, a process referred to as receptor matching (Borodinsky and Spitzer, 2007; Dulcis and Spitzer, 2008; Dulcis et al., 2013). Although a correlation between switching and receptor matching has been repeatedly observed, how one influences the other is not yet understood. In the Xenopus larva, developing striated trunk-muscle cells express multiple classes of transmitter receptors, most of which disappear following cholinergic innervation of the neuromuscular junction and expansion of acetylcholine receptor expression. Exogenous activation of glutamate receptors expressed on these muscle cells in the absence of innervation is sufficient and necessary for upregulation of these receptors, suggesting that matching is achieved by increasing the expression of receptors that are normally expressed at low levels (HammondWeinberger et al., 2020). Whether this model of transmitterstimulated upregulation of preexisting receptors applies to receptor matching at neuron-to-neuron synapses is untested, both during development and in the adult nervous system, but transmitter receptors expressed extrasynaptically on the synapse-free cell bodies of invertebrate and vertebrate neurons are consistent with this notion (Sargent et al., 1977; Pellegrino and Simonneau, 1984; White, 1990; Genzen et al., 2001; Moraes et al., 2014). Transmitter receptors expressed extrasynaptically adjacent to synapses have been most studied in the context of synaptic spillover, however; receptor matching following transmitter switching is an understudied subject. 


\section{Glia}

Do glia facilitate or prevent transmitter switching?

Like other forms of neuroplasticity, transmitter switching is both activity and BDNF dependent and can be non-cell autonomous (Marek et al., 2010; Guemez-Gamboa et al., 2014; Meng et al., 2018). Glial cells contribute to plasticity by actively responding to neuronal activation and reciprocally releasing neuroactive gliotransmitters and neurotrophic factors to regulate neuronal activity and neuroplasticity [glial regulation of synapse number (Chung et al., 2015), synaptic connectivity (Eroglu and Barres, 2010), and neuronal excitability (Tan et al., 2017)]. Astrocytes recycle the precursor of $\mathrm{BDNF}$ (proBDNF) that is secreted by neurons as a proneurotrophin after LTP, driving further proBDNF release to adjacent neurons and thus expanding BDNF action (Vignoli et al., 2016). Moreover, blocking the glial recycling of BDNF by specifically knocking out BDNF receptors in glial cells leads to failures in memory consolidation (Vignoli et al., 2016). Microglial cells also release BDNF (Parkhurst et al., 2013). When microglia are selectively depleted from the brain or when microglial BDNF is removed using a CX3CR1-CreER ${ }^{\mathrm{T}}$ mouse line, mice show deficits in learning tasks and a reduction in motor learning-dependent synapse formation (Parkhurst et al., 2013). It will not be surprising if glia also contribute to neurotransmitter switching through the regulation of neuronal activity and extracellular BDNF. Transgenic mouse lines and Cre-dependent gene transfer tools have been developed to allow both loss-of-function and gain-of-function investigations of glia. Success in harnessing these tools will be the basis for investigation of glial contribution to transmitter switching both during development and in the adult and from health to disease.

\section{Can glia switch gliotransmitters?}

Transmitter switching may not be restricted to neurons. Glial cells release gliotransmitters, including glutamate, GABA, ATP, and d-serine, to facilitate communication between neurons and other glial cells (Harada et al., 2016). Although it is unclear whether a single glial cell can release all transmitters or only some of them, the storage and release of different gliotransmitters are spatially and temporally regulated in transmitter-specific ways. For example, glutamate is stored in synaptic vesicle-like compartments and can be released through vesicles, cystine/glutamate antiporters, purinoceptors, and gap junctions (Harada et al., 2016), whereas ATP is stored in lysosomes and released through lysosomal exocytosis (Zhang et al., 2007; Dou et al., 2012). The release of these gliotransmitters is tightly coupled to neuronal activity and modulates synaptic function. For instance, in mouse hippocampal slices, low-frequency or short-duration stimulation patterns at CA3-CA1 synapses induce glutamate release from astrocytes, resulting in synaptic potentiation. In contrast, highfrequency or prolonged stimulation patterns induce the release of purinergic amines (ATP/adenosine) leading to synaptic depression at the same synapse (Covelo and Araque, 2018). Astrocytes in the olfactory bulb release GABA and glutamate in a target celldependent manner (Kozlov et al., 2006). Astrocytes can invert the sign of the synapse by converting inhibitory signals from inter neurons into excitatory signals by releasing glutamate (Perea et al., 2016). Thus, an imbalance in the release of these gliotransmitters may result in altered neuronal activity with behavioral consequences. Astrocyte expression of a variety of transmitter receptors (Fields et al., 2015; Boddum et al., 2016) (potentially all transmitter receptors known so far) (Verkhratsky and Nedergaard, 2018), dynamically regulated in response to environmental changes
(Kuhn et al., 2004), positions astrocytes to monitor and respond to changes in activity levels of a circuit.

If astrocytes not only decode neuronal activity by modulating the gliotransmitters released, but also respond to changes in neuronal activity by regulating the combination of gliotransmitters expressed, this will argue for gliotransmitter switching. Glia acquire transmitters by two major pathways: (1) uptake from synapses via transporters; and (2) biosynthesis through related enzymes (Henn et al., 1974; Yoon and Lee, 2014). The neurotransmitters released at the synapse are taken up both by neuronal and glial cells, giving rise to a transmitter flux between neurons and astrocytes. Thus, the transmitter changes in neurons may be reflected in glia and constitute one form of gliotransmitter switching. Alternatively, some gliotransmitter switching may be more akin to neurotransmitter switching, in which glia revise their biosynthesis of certain transmitters in an activity-dependent manner. Studies of gliotransmitter switching could increase the complexity of neuronal networks but would be a conceptual addition to our understanding of brain plasticity.

\section{Brain-wide analysis of neurotransmitter switching}

Do single stimuli cause multiple foci of transmitter switching throughout the brain? As noted above, when an environmental stimulus induces sustained changes in neuronal activity in a specific brain region, a subset of the neurons within that region can switch their neurotransmitters. However, the same environmental stimulus can produce changes in brain activity in more than one region of the brain, as revealed by c-fos staining (Li and Spitzer, 2020), raising the question of the full extent of this plasticity. For example, mice that have run on a running wheel for a week exhibit both an ACh-to-GABA switch in the PPN in the midbrain, where the switch regulates motor skill learning (Li and Spitzer, 2020), and a NPY-to-glutamate switch in the hilus of the DG, where the switch regulates episodic memory (Zambetti et al., 2017). There is no evidence of neuronal connections between the PPN and DG, but the observation that running triggers switching in both regions seems unlikely to be a coincidence. The co-occurrence of transmitter switching across multiple brain regions may have an evolutionary advantage. A wild mouse requires motor coordination to escape from its predators. At the same time, for a successful escape, the mouse also relies on context-dependent episodic memory of a good hiding place. By promoting both motor skill learning and episodic learning and memory, the routine act of voluntary running gives a mouse a better chance to escape from a predator than a mouse that does not exercise. Transmitter switching in several different brain regions may synergistically contribute to a complex behavior (Fig. 3).

The discovery that transmitter switching occurs in more than one region of the brain in response to the same stimulus raises an intriguing question. Can one brain area undergo switching first and, like dominoes, stimulate a cascade of sequential transmitter switching in the brain? If so, it could potentially trigger secondary, tertiary, or further instances of switching. Investigation of such potential transmitter-switching cascades may be particularly relevant to understanding the role of transmitter switching in mental illness. In a scenario in which switching occurs in a single brain region that projects to multiple regions (Fig. 2), areas receiving the altered input may also experience transmitter switching. Efforts to override switching in all regions would be a substantial challenge. However, identifying and overriding the initial switch would be a game changer, because no secondary or tertiary switching would occur. 


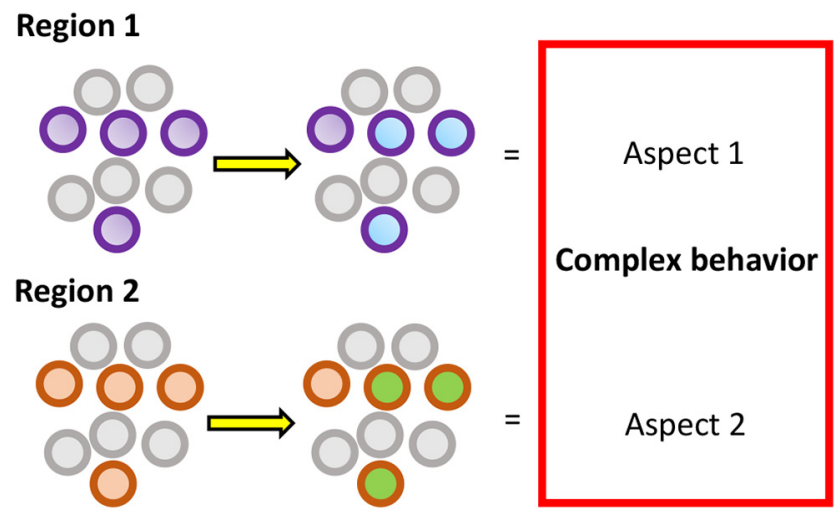

Figure 3. Synergistic transmitter switching. Brain regions 1 and 2 respond with transmitter switching after stimulation (yellow arrows). The two regions regulate different but interdependent aspects of a complex behavior (red rectangle) to exert a synergistic effect. For example, running triggers switching in both the PPN and in the DG that leads to enhanced motor skill learning and enhanced episodic memory, respectively, which synergistically promote the chance of the escape of a mouse from a predator.

downstream brain region with electrophysiological or optical methods before and after the exposure of the animals to experimental stimuli that induce switching and examine postsynaptic potentials or neuronal activity in the downstream regions.

If a change in activity is detected, current methodologies that combine transgenic Cre lines and gene transfer tools can be used to override transmitter switching and determine whether it affects the activity of neurons in downstream brain regions. Combining retrograde tracing with Cre-dependent and Flp-dependent systems will enable studies determining whether overriding switching in the neurons that project to a specific target affects behavior (Fig. 4). The approach can take advantage of a novel retrograde viral vector (RG-EIAV-DIO-Flp) that is based on pseudotyping equine infectious anemia lentivirus (EIAV) and modified with a fusion protein (FuG-B2), linking extracellular and transmembrane domains of the rabies glycoprotein to the cytoplasmic domain of vesicular stomatitis virus glycoprotein (Knowland et al., 2017). These manipulations require mice in which Cre is specifically expressed by the population of neurons that are expected to switch transmitters. If the RG-EIAV-DIO-Flp vector is injected into the brain region that is innervated by neurons that switch transmitters, it will allow Cre-on expression of Flp recombinase. Flp-ON AAV (adeno-associated virus) vectors (AAV-fDIO-ORF or AAV-fDIO-shRNA) can then be injected into the brain region in which transmitter switching occurs, enabling Flp-on expression of genes to restore a lost transmitter or Flp-on expression of an shRNA sequence to suppress a gained transmitter. In this way, one can study how overriding the switch in a subpopulation of switching neurons with a specific projection target affects behavior.

\section{Therapy \\ Transmitter switching in human subjects}

A major goal of neuroscience research is to understand how the human brain works and develop effective therapies to prevent, treat, and cure neurologic and psychiatric disorders. Screening for transmitter switching in the adult rodent brain can identify a pool of candidates for transmitter switching in humans. Staining molecular markers for transmit-

\section{Behavior}

How does transmitter switching produce changes in behavior? Transmitter switching usually changes the transmitter of a neuron from excitatory to inhibitory or vice versa, which is likely to change the function of a neural circuit and network. However, how transmitter switching affects the neural circuit and eventually behavior is not yet clear. Elegant methods have been developed to identify specific neural circuits, and mesoscale projectomes of single neurons can be mapped in the mammalian brain (Knowland et al., 2017; Ren et al., 2018). Using currently available tracing tools, one can determine the projection targets of transmitterswitching neurons (Li and Spitzer, 2020). Further functional studies can then be performed to investigate how transmitter switching affects the neural circuit. One approach is to activate the neurons with optogenetic tools and record from the ter identity in human brain slices and comparing results from postmortem brains of individuals who experienced different circumstances may help to identify the presence of transmitter switching in human subjects (Aumann et al., 2016). Tissue is available from brain banks that are distributed worldwide (https:/www.brainbank.nl/about-us/brain-net-europe/). These brain banks collect postmortem human brains and distribute samples to the research community to foster research into human CNS function and diseases such as Alzheimer's disease, Parkinson's disease, and stroke (Kretzschmar, 2009). Brain banks provide human brain sections from subjects of different ages, which enable studies of developing, young, and aged brains. Brains that were donated by subjects who had received deep brain electrical stimulation (DBS), a procedure that involves implanting electrodes 
into the brain to treat neurologic and psychological disorders via delivery of electrical impulses (Holtzheimer and Mayberg, 2011; Ellens and Leventhal, 2013; Delaloye and Holtzheimer, 2014), can also be studied to determine whether the benefits of DBS may involve switching transmitters (Dela Cruz et al., 2015).

\section{Invasive therapy using gene transfer tools}

Viral vectors have been used in mice and rats to override switching by restoring a lost transmitter (through gene expression) or by preventing gain of a transmitter (by RNA interference). This strategy prevents switching-induced behavioral alterations (Li and Spitzer, 2020). Viral vectors can also be used to artificially induce transmitter switching by driving the expression of one transmitter and suppressing the expression of another, which may be sufficient to induce behavioral changes. However, this hypothesis remains to be tested. Considering the invasive modes of delivery and the high costs, viral vectors are currently not applicable to humans. However, the combination of CRISPR-mediated genome editing (Chen et al., 2016; Kang et al., 2019) together with viral vector-mediated gene expression in nonhuman primate brains can potentially be applied to investigate the behavioral consequences of switching in the primate brain. Recent clinical trials have shown success in using $\mathrm{AAV}$ vectors as an in vivo gene transfer tool (Colella et al., 2017), suggesting that if viral vectors for inducing or preventing switching could be developed for humans, they have the potential to become a novel approach for treatment of psychiatric and neurologic diseases.

\section{Noninvasive behavioral therapy}

Natural sensory stimuli, such as changes in day length or chronic physical exercise, trigger transmitter switching and affect behavior. This causal link between switching and behavioral alteration prompts exploration of behavioral therapy for the induction of switching in specific brain regions, and may in the future provide a noninvasive strategy for treatment of brain disorders. It is important to keep in mind that transmitter switching can spontaneously reverse after the cessation of the inducing stimulus (Li and Spitzer, 2020). However, in other cases, and specifically when transmitter switching is induced by a stressor and results in detrimental behaviors, both the switch and the behavioral changes it engenders appear to be stable (Dulcis et al., 2013; Li and Spitzer, 2019). The different degrees of reversal may be caused by differential impacts on hormone levels of predictable or rewarding versus unpredictable or aversive stress (Stranahan et al., 2008). For stress-induced switching that does not reverse spontaneously, exposure to a new environmental stimulus that can result in the reversal of the detrimental switch may lead to future therapeutic options.

In the short term, one can test whether a well studied beneficial stimulus can alleviate a behavior by reversing the initial transmitter switch. For example, the detrimental effects of postnatal maternal separation stress in rats can be diminished by postweaning exposure to an enriched environment (Dandi et al., 2018), and social isolation of young mice induces alterations in prefrontal cortex function that are relieved by subsequent resocialization (Makinodan et al., 2012). If transmitter switches of opposite signs are involved in the initial induction and the later amelioration of the dysfunctional behavior, this will motivate research on the therapeutic potential of transmitter switching. Study of animal models of illnesses such as autism, post-traumatic stress disorder, and drug abuse can be useful in determining the role of switching in these disorders, which may lead to the development of cognitive behavioral therapies that produce similar changes in the brains of human subjects. Over the long term, one can envision the development of a database of the environmental stimuli that induce transmitter switching, with the brain regions, cell types, and neurotransmitters involved, along with the associated behaviors, including pathologic symptoms.

\section{Conclusion}

This article has identified particularly salient questions about the operation of transmitter switching, the answers to which will open new lines of investigation. It is not meant to be complete and is a preliminary survey of the possibilities for productive research. The principal focus has been on the adult mammalian brain, although the issues may be addressed at other stages and in other animals. We have outlined the results of recent studies and described tools that will be useful for high-throughput screening of transmitter switching. We have discussed the cellular analysis and molecular mechanisms by which transmitter switching is regulated and how it is associated with changes in behavior. Extension of the current studies on model organisms to human subjects is appealing, since the ability to switch neurotransmitters may lead to the development of new therapeutic treatments for neurologic and psychiatric disorders.

\section{References}

Alpert NM, Badgaiyan RD, Livni E, Fischman AJ (2003) A novel method for noninvasive detection of neuromodulatory changes in specific neurotransmitter systems. Neuroimage 19:1049-1060.

Amrein I, Isler K, Lipp HP (2011) Comparing adult hippocampal neurogenesis in mammalian species and orders: influence of chronological age and life history stage. Eur J Neurosci 34:978-987.

Aumann TD, Raabus M, Tomas D, Prijanto A, Churilov L, Spitzer NC, Horne MK (2016) Differences in number of midbrain dopamine neurons associated with summer and winter photoperiods in humans. PLoS One 11:e0158847.

Baker H (1990) Unilateral, neonatal olfactory deprivation alters tyrosine hydroxylase expression but not aromatic amino acid decarboxylase or GABA immunoreactivity. Neuroscience 36:761-771.

Barnes CA (1979) Memory deficits associated with senescence: a neurophysiological and behavioral study in the rat. J Comp Physiol Psychol 93:74104.

Bertuzzi M, Chang W, Ampatzis K (2018) Adult spinal motoneurons change their neurotransmitter phenotype to control locomotion. Proc Natl Acad Sci U S A 115:E9926-E9933.

Bizon JL, Lee HJ, Gallagher M (2004) Neurogenesis in a rat model of agerelated cognitive decline. Aging Cell 3:227-234.

Boddum K, Jensen TP, Magloire V, Kristiansen U, Rusakov DA, Pavlov I, Walker MC (2016) Astrocytic GABA transporter activity modulates excitatory neurotransmission. Nat Commun 7:13572.

Borodinsky LN, Spitzer NC (2007) Activity-dependent neurotransmitter-receptor matching at the neuromuscular junction. Proc Natl Acad Sci U S A 104:335-340.

Borodinsky LN, Root CM, Cronin JA, Sann SB, Gu X, Spitzer NC (2004) Activity-dependent homeostatic specification of transmitter expression in embryonic neurons. Nature 429:523-530.

Bouabe H, Okkenhaug K (2013) Gene targeting in mice: a review. Methods Mol Biol 1064: 315-336.

Burgio G (2018) Redefining mouse transgenesis with CRISPR/Cas9 genome editing technology. Genome Biol 19:41.

Chen T-W, Wardill TJ, Sun Y, Pulver SR, Renninger SL, Baohan A, Schreiter ER, Kerr RA, Orger MB, Jayaraman V, Looger LL, Svoboda K, Kim DS (2013) Ultrasensitive fluorescent proteins for imaging neuronal activity. Nature 499:295-300.

Chen Y, Niu Y, Ji W (2016) Genome editing in nonhuman primates: approach to generating human disease models. J Intern Med 280:246-251.

Chung W, Allen N, Eroglu C (2015) Astrocytes control synapse formation, function, and elimination. Cold Spring Harb Perspect Biol 7:a020370. 
Citri A, Malenka RC (2008) Synaptic plasticity: multiple forms, functions, and mechanisms. Neuropsychopharmacology 33:18-41.

Colella P, Ronzitti G, Mingozzi F (2017) Emerging Issues in AAV-mediated in vivo gene therapy. Mol Ther Methods Clin Dev 8:87-104.

Cooper DL (2006) Broca's arrow: evolution, prediction, and language in the brain. Anat Rec B New Anat 289:9-24.

Covelo A, Araque A (2018) Neuronal activity determines distinct gliotransmitter release from a single astrocyte. Elife 7:e32237.

Dandi E, Kalamari A, Touloumi O, Lagoudaki R, Nousiopoulou E, Simeonidou C, Spandou E, Tata DA (2018) Beneficial effects of environmental enrichment on behavior, stress reactivity and synaptophysin/ BDNF expression in hippocampus following early life stress. Int J Dev Neurosci 67:19-32.

Dela Cruz JAD, Hescham S, Adriaanse B, Campos FL, Steinbusch HWM, Rutten BPF, Temel Y, Jahanshahi A (2015) Increased number of TH-immunoreactive cells in the ventral tegmental area after deep brain stimulation of the anterior nucleus of the thalamus. Brain Struct Funct 220: 3061-3066.

Delaloye S, Holtzheimer P (2014) Deep brain stimulation in the treatment of depression. Dialogues Clin Neurosci 16:83-91.

Demarque M, Spitzer NC (2010) Activity-dependent expression of Lmx1b regulates specification of serotonergic neurons modulating swimming behavior. Neuron 67:321-334.

Deupree DL, Turner DA, Watters CL (1991) Spatial performance correlates with in vitro potentiation in young and aged Fischer 344 rats. Brain Research 554:1-9.

Dieguez D Jr, Barea-Rodriguez EJ (2004) Aging impairs the late phase of longterm potentiation at the medial perforant path-CA3 synapse in awake rats. Synapse 52:53-61.

Dodt H-U, Leischner U, Schierloh A, Jährling N, Mauch CP, Deininger K, Deussing JM, Eder M, Zieglgänsberger W, Becker K (2007) Ultramicroscopy: three-dimensional visualization of neuronal networks in the whole mouse brain. Nat Methods 4:331-336.

Dou Y, Wu H-j, Li H-q, Qin S, Wang Y-e, Li J, Lou H-f, Chen Z, Li X-m, Luo Q-m, Duan S (2012) Microglial migration mediated by ATP-induced ATP release from lysosomes. Cell Res 22:1022-1033.

Dulcis D, Spitzer NC (2008) Illumination controls differentiation of dopamine neurons regulating behaviour. Nature 456:195-201.

Dulcis D, Spitzer NC (2012) Reserve pool neuron transmitter respecification: Novel neuroplasticity. Dev Neurobiol 72:465-474.

Dulcis D, Jamshidi P, Leutgeb S, Spitzer NC (2013) Neurotransmitter switching in the adult brain regulates behavior. Science 340:449-453.

Dulcis D, Lippi G, Stark CJ, Do LH, Berg DK, Spitzer NC (2017) Neurotransmitter switching regulated by miRNAs controls changes in social preference. Neuron 95:1319-1333.

Ellens D, Leventhal D (2013) Review: electrophysiology of basal ganglia and cortex in models of Parkinson disease. J Parkinsons Dis 3:241-254.

Enwere E, Shingo T, Gregg C, Fujikawa H, Ohta S, Weiss S (2004) Aging results in reduced epidermal growth factor receptor signaling, diminished olfactory neurogenesis, and deficits in fine olfactory discrimination. J Neurosci 24:8354-8365.

Eroglu C, Barres B (2010) Regulation of synaptic connectivity by glia. Nature 468:223-231.

Fenno LE, Mattis J, Ramakrishnan C, Hyun M, Lee SY, He M, Tucciarone J, Selimbeyoglu A, Berndt A, Grosenick L, Zalocusky KA, Bernstein H, Swanson H, Perry C, Diester I, Boyce FM, Bass CE, Neve R, Huang ZJ, Deisseroth K (2014) Targeting cells with single vectors using multiple-feature Boolean logic. Nat Methods 11:763-772.

Fields R, Woo D, Basser P (2015) Glial regulation of the neuronal connectome through local and long-distant communication. Neuron 86:374-386.

Genzen JR, Van Cleve W, McGehee DS (2001) Dorsal root ganglion neurons express multiple nicotinic acetylcholine receptor subtypes. J Neurophysiol 86:1773-1782.

Godavarthi S, Spitzer NC (2017) Environmental models of autism engage neurotransmitter switching in prefrontal cortex. Soc Neurosci Abstr 43:661.06.

Gong H, Xu D, Yuan J, Li X, Guo C, Peng J, Li Y, Schwarz LA, Li A, Hu B, Xiong B, Sun Q, Zhang Y, Liu J, Zhong Q, Xu T, Zeng S, Luo Q (2016) High-throughput dual-colour precision imaging for brain-wide connectome with cytoarchitectonic landmarks at the cellular level. Nat Commun 7:12142.

Gould SJ, Vrba ES (1982) Exaptation-a missing term in the science of form. Paleobiology 8:4-15.
Grant MP, Francis NJ, Landis SC (1995) The role of acetylcholine in regulating secretory responsiveness in rat sweat glands. Mol Cell Neurosci 6:32-42.

Guemez-Gamboa A, Xu L, Meng D, Spitzer NC (2014) Non-cell-autonomous mechanism of activity-dependent neurotransmitter switching. Neuron 82:1004-1016

Hama H, Hioki H, Namiki K, Hoshida T, Kurokawa H, Ishidate F, Kaneko T, Akagi T, Saito T, Saido T, Miyawaki A (2015) ScaleS: an optical clearing palette for biological imaging. Nat Neurosci 18:1518-1529.

Hammond-Weinberger DR, Wang Y, Glavis-Bloom A, Spitzer NC (2020) Mechanism for neurotransmitter-receptor matching. Proc Natl Acad Sci U S A 117:4368-4374

Harada K, Kamiya T, Tsuboi T (2016) Gliotransmitter release from astrocytes: functional, developmental, and pathological implications in the brain. Front Neurosci 9:499.

He X-B, Yi S-H, Rhee Y-H, Kim H, Han Y-M, Lee S-H, Lee H, Park C-H, Lee Y-S, Richardson E, Kim B-W, Lee S-H (2011) Prolonged membrane depolarization enhances midbrain dopamine neuron differentiation via epigenetic histone modifications. Stem Cells 29:1861-1873.

Heiman M, Kulicke R, Fenster RJ, Greengard P, Heintz N (2014) Cell typespecific mRNA purification by translating ribosome affinity purification (TRAP). Nat Protoc 9:1282-1291.

Heiss WD, Herholz K (2006) Brain receptor imaging. J Nucl Med 47:302-312.

Henn FA, Goldstein MN, Hamberger A (1974) Uptake of the neurotransmitter candidate glutamate by glia. Nature 249:663-664.

Holtzheimer PE, Mayberg HS (2011) Deep brain stimulation for psychiatric disorders. Annu Rev Neurosci 34:289-307.

Hull EM, Dominguez JM (2007) Sexual behavior in male rodents. Horm Behav 52:45-55.

Jensen P, Dymecki SM (2014) Essentials of recombinase-based genetic fate mapping in mice. Methods Mol Biol 1092:437-454.

Kang Y, Chu C, Wang F, Niu Y (2019) CRISPR/Cas9-mediated genome editing in nonhuman primates. Dis Model Mech 12:dmm039982.

Katona G, Szalay G, Maák P, Kaszás A, Veress M, Hillier D, Chiovini B, Vizi ES, Roska B, Rózsa B (2012) Fast two-photon in vivo imaging with three-dimensional random-access scanning in large tissue volumes. Nat Methods 9:201208 .

Knowland D, Lilascharoen V, Pacia CP, Shin S, Wang EH-J, Lim BK (2017) Distinct ventral pallidal neural populations mediate separate symptoms of depression. Cell 170:284-297.

Kolb B, Gibb R (2011) Brain plasticity and behaviour in the developing brain. J Can Acad Child Adolesc Psychiatry 20:265-276.

Kozlov AS, Angulo MC, Audinat E, Charpak S (2006) Target cell specific modulation of neuronal activity by astrocytes. Proc Natl Acad Sci U S A 103:10058-10063.

Kretzschmar H (2009) Brain banking: opportunities, challenges and meaning for the future. Nat Rev Neurosci 10:70-78.

Kuhn SA, van Landeghem FKH, Zacharias R, Färber K, Rappert A, Pavlovic S, Hoffmann A, Nolte C, Kettenmann H (2004) Microglia express GABA (B) receptors to modulate interleukin release. Mol Cell Neurosci 25: 312-322.

Lake BB, Ai R, Kaeser GE, Salathia NS, Yung YC, Liu R, Wildberg A, Gao D, Fung H-L, Chen S, Vijayaraghavan R, Wong J, Chen A, Sheng X, Kaper F, Shen R, Ronaghi M, Fan J-B, Wang W, Chun J, et al. (2016) Neuronal subtypes and diversity revealed by single-nucleus RNA sequencing of the human brain. Science 352:1586-1590.

Lancelot S, Zimmer L (2010) Small-animal positron emission tomography as a tool for neuropharmacology. Trends Pharmacol Sci 31:411-417.

Li H, Spitzer NC (2019) Role of transmitter plasticity in the development of PTSD. Soc Neurosci Abstr 45:104.04.

Li H, Spitzer NC (2020) Exercise enhances motor skill learning by neurotransmitter switching in the adult midbrain. Nat Commun, in press.

Li L, Tasic B, Micheva KD, Ivanov VM, Spletter ML, Smith SJ, Luo L (2010) Visualizing the distribution of synapses from individual neurons in the mouse brain. PLoS One 5:e11503.

Liu Y, Krantz DE, Waites C, Edwards RH (1999) Membrane trafficking of neurotransmitter transporters in the regulation of synaptic transmission. Trends Cell Biol 9:356-363.

Lopatina OL, Malinovskaya NA, Komleva YK, Gorina YV, Shuvaev AN, Olovyannikova RY, Belozor OS, Belova OA, Higashida H, Salmina AB (2019) Excitation/inhibition imbalance and impaired neurogenesis in neurodevelopmental and neurodegenerative disorders. Rev Neurosci 30:807-820. 
Mahmoudi P, Veladi H, Pakdel FG (2017) Optogenetics, tools and applications in neurobiology. J Med Signals Sens 7:71-79.

Makinodan M, Rosen KM, Ito S, Corfas G (2012) A critical period for social experience-dependent oligodendrocyte maturation and myelination. Science 337:1357-1360.

Marek K, Kurtz L, Spitzer NC (2010) cJun integrates calcium activity and tlx3 expression to regulate neurotransmitter specification. Nat Neurosci 13:944950.

Meng D, Li H-Q, Deisseroth K, Leutgeb S, Spitzer NC (2018) Neuronal activity regulates neurotransmitter switching in the adult brain following lightinduced stress. Proc Natl Acad Sci U S A 115:5064-5071.

Mentis GZ, Alvarez FJ, Bonnot A, Richards DS, Gonzalez-Forero D, Zerda R, O'Donovan MJ (2005) Noncholinergic excitatory actions of motoneurons in the neonatal mammalian spinal cord. Proc Natl Acad Sci U S A 102:7344-7349.

Metzger D, Chambon P (2001) Site- and time-specific gene targeting in the mouse. Methods 24:71-80.

Moraes ER, Kushmerick C, Naves LA (2014) Characteristics of dorsal root ganglia neurons sensitive to substance P. Mol Pain 10:73.

Nabekura J, Katsurabayashi S, Kakazu Y, Shibata S, Matsubara A, Jinno S, Mizoguchi Y, Sasaki A, Ishibashi H (2004) Developmental switch from GABA to glycine release in single central synaptic terminals. Nat Neurosci 7:17-23.

Nectow AR, Moya MV, Ekstrand MI, Mousa A, McGuire KL, Sferrazza CE, Field BC, Rabinowitz GS, Sawicka K, Liang Y, Friedman JM, Heintz N, Schmidt EF (2017) Rapid molecular profiling of defined cell types using viral TRAP. Cell Rep 19:655-667.

Newberg AB, Moss AS, Monti DA, Alavi A (2011) Positron emission tomography in psychiatric disorders. Ann N Y Acad Sci 1228: E13-E25.

Nishimaru H, Restrepo CE, Ryge J, Yanagawa Y, Kiehn O (2005) Mammalian motor neurons corelease glutamate and acetylcholine at central synapses. Proc Natl Acad Sci U S A 102:5245-5249.

Norris CM, Korol DL, Foster TC (1996) Increased susceptibility to induction of long-term depression and long-term potentiation reversal during aging. J Neurosci 16:5382-5392.

Okaty BW, Freret ME, Rood BD, Brust RD, Hennessy ML, deBairos D, Kim JC, Cook MN, Dymecki SM (2015) Multi-scale molecular deconstruction of the serotonin neuron system. Neuron 88:774-791.

Park Y-G, Sohn CH, Chen R, McCue M, Yun DH, Drummond GT, Ku T, Evans NB, Oak HC, Trieu W, Choi H, Jin X, Lilascharoen V, Wang J, Truttmann MC, Qi HW, Ploegh HL, Golub TR, Chen S-C, Frosch MP, et al. (2019) Protection of tissue physicochemical properties using polyfunctional crosslinkers. Nat Biotechnol 37:73-83.

Parkhurst CN, Yang G, Ninan I, Savas JN, Yates JR, Lafaille JJ, Hempstead BL, Littman DR, Gan W-B (2013) Microglia promote learning-dependent synapse formation through brain-derived neurotrophic factor. Cell 155:15961609.

Patterson PH, Chun LL (1977) The induction of acetylcholine synthesis in primary cultures of dissociated rat sympathetic neurons. I. Effects of conditioned medium. Dev Biol 56:263-280.

Pellegrino M, Simonneau M (1984) Distribution of receptors for acetylcholine and 5-hydroxytryptamine on identified leech neurones growing in culture. J Physiol 352:669-684.

Penn AA, Shatz CJ (1999) Brain waves and brain wiring: the role of endogenous and sensory-driven neural activity in development. Pediatr Res 45: $447-458$.

Perea G, Gómez R, Mederos S, Covelo A, Ballesteros JJ, Schlosser L, Hernández-Vivanco A, Martín-Fernández M, Quintana R, Rayan A, Díez A, Fuenzalida M, Agarwal A, Bergles DE, Bettler B, Manahan-Vaughan D, Martín ED, Kirchhoff F, Araque A (2016) Activity-dependent switch of GABAergic inhibition into glutamatergic excitation in astrocyte-neuron networks. Elife 5:e20362.

Pereira M, Morrell JI (2011) Functional mapping of the neural circuitry of rat maternal motivation: effects of site-specific transient neural inactivation. J Neuroendocrinol 23:1020-1035.

Pocock R, Hobert O (2010) Hypoxia activates a latent circuit for processing gustatory information in C. elegans. Nat Neurosci 13:610-614

Prakash N, Stark CJ, Keisler MN, Luo L, Der-Avakian A, Dulcis D (2020) Serotonergic plasticity in the dorsal raphe nucleus characterizes susceptibility and resilience to anhedonia. J Neurosci 40:569- 584 .

Pratelli M, Spitzer NC (2019) Phencyclidine-induced neurotransmitter switching in the mouse prelimbic cortex and its behavioral outcomes. Soc Neurosci Abstr 45:104.01.
Pritchard R, Chen H, Romoli B, Spitzer NC, Dulcis D (2020) Photoperiodinduced neurotransmitter plasticity declines with aging: an epigenetic regulation? J Comp Neurol 528:199-210.

Ragan T, Kadiri LR, Venkataraju KU, Bahlmann K, Sutin J, Taranda J, ArgandaCarreras I, Kim Y, Seung HS, Osten P (2012) Serial two-photon tomography for automated ex vivo mouse brain imaging. Nat Methods 9:255258.

Ren J, Friedmann D, Xiong J, Liu CD, Ferguson BR, Weerakkody T, DeLoach KE, Ran C, Pun A, Sun Y, Weissbourd B, Neve RL, Huguenard J, Horowitz MA, Luo L (2018) Anatomically defined and functionally distinct dorsal raphe serotonin sub-systems. Cell 175:472-487.

Rice OV, Gatley SJ, Shen J, Huemmer CL, Rogoz R, DeJesus OT, Volkow ND, Gifford AN (2001) Effects of endogenous neurotransmitters on the in vivo binding of dopamine and 5-HT radiotracers in mice. Neuropsychopharmacology 25:679-689.

Romoli B, Lozada AF, Sandoval IM, Manfredsson FP, Hnasko TS, Berg DK, Dulcis D (2019) Neonatal nicotine exposure primes midbrain neurons to a dopaminergic phenotype and increases adult drug consumption. Biol Psychiatry 86:344-355.

Rosenberg AB, Roco CM, Muscat RA, Kuchina A, Sample P, Yao Z, Graybuck LT, Peeler DJ, Mukherjee S, Chen W, Pun SH, Sellers DL, Tasic B, Seelig G (2018) Single-cell profiling of the developing mouse brain and spinal cord with split-pool barcoding. Science 360:176-182.

Sargent PB, Yau KW, Nicholls JG (1977) Extrasynaptic receptors on cell bodies of neurons in central nervous system of the leech. J Neurophysiol 40:446-452.

Sauer B (1998) Inducible gene targeting in mice using the Cre/lox system. Methods 14:381-392.

Schotzinger RJ, Landis SC (1988) Cholinergic phenotype developed by noradrenergic sympathetic neurons after innervation of a novel cholinergic target in vivo. Nature 335:637-639.

Seiriki K, Kasai A, Hashimoto T, Schulze W, Niu M, Yamaguchi S, Nakazawa T, Inoue K-I, Uezono S, Takada M, Naka Y, Igarashi H, Tanuma M, Waschek JA, Ago Y, Tanaka KF, Hayata-Takano A, Nagayasu K, Shintani N, Hashimoto R, et al. (2017) High-speed and scalable whole-brain imaging in rodents and primates. Neuron 94:1085-1100.

Seiriki K, Kasai A, Nakazawa T, Niu M, Naka Y, Tanuma M, Igarashi H, Yamaura K, Hayata-Takano A, Ago Y, Hashimoto H (2019) Whole-brain block-face serial microscopy tomography at subcellular resolution using FAST. Nat Protoc 14:1509-1529.

Serrano-Saiz E, Poole RJ, Felton T, Zhang F, De La Cruz ED, Hobert O (2013) Modular control of glutamatergic neuronal identity in C. elegans by distinct homeodomain proteins. Cell 155:659-673.

Sohal VS, Rubenstein JLR (2019) Excitation-inhibition balance as a framework for investigating mechanisms in neuropsychiatric disorders. Mol Psychiatry 24:1248-1257.

Spitzer NC (2012) Activity-dependent neurotransmitter respecification. Nat Rev Neurosci 13:94-106.

Spitzer NC (2017) Neurotransmitter switching in the developing and adult brain. Annu Rev Neurosci 40:1-19.

Spriggs MJ, Cadwallader CJ, Hamm JP, Tippett LJ, Kirk IJ (2017) Age-related alterations in human neocortical plasticity. Brain Res Bull 130:53-59.

Sternson SM, Roth BL (2014) Chemogenetic tools to interrogate brain functions. Annu Rev Neurosci 37:387-407.

Stranahan AM, Lee K, Mattson MP (2008) Central mechanisms of HPA axis regulation by voluntary exercise. Neuromolecular Med 10:118-127.

Stuart T, Satija R (2019) Integrative single-cell analysis. Nat Rev Genet 20:257272.

Su Y, Shin J, Zhong C, Wang S, Roychowdhury P, Lim J, Kim D, Ming G-L, Song H (2017) Neuronal activity modifies the chromatin accessibility landscape in the adult brain. Nat Neurosci 20:476-483.

Susaki EA, Tainaka K, Perrin D, Kishino F, Tawara T, Watanabe TM, Yokoyama C, Onoe H, Eguchi M, Yamaguchi S, Abe T, Kiyonari H, Shimizu Y, Miyawaki A, Yokota H, Ueda HR (2014) Whole-brain imaging with single-cell resolution using chemical cocktails and computational analysis. Cell 157:726-739.

Tamamaki N, Yanagawa Y, Tomioka R, Miyazaki J-I, Obata K, Kaneko T (2003) Green fluorescent protein expression and colocalization with calretinin, parvalbumin, and somatostatin in the GAD67-GFP knock-in mouse. J Comp Neurol 467:60-79.

Tan Z, Liu Y, Xi W, Lou H-F, Zhu L, Guo Z, Mei L, Duan S (2017) Gliaderived ATP inversely regulates excitability of pyramidal and CCK-positive neurons. Nat Commun 8:13772 
Tomer R, Ye L, Hsueh B, Deisseroth K (2014) Advanced CLARITY for rapid and high-resolution imaging of intact tissues. Nat Protoc 9:16821697.

Tritsch N, Granger A, Sabatini BL (2016) Mechanisms and functions of GABA co-release. Nat Rev Neurosci 17:139-145.

Turrigiano GG (2008) The self-tuning neuron: synaptic scaling of excitatory synapses. Cell 135:422-435.

Verkhratsky A, Nedergaard M (2018) Physiology of astroglia. Physiol Rev 98:239-389.

Vignoli B, Battistini G, Melani R, Blum R, Santi S, Berardi N, Canossa M (2016) Peri-synaptic glia recycle brain-derived neurotrophic factor for LTP stabilization and memory retention. Neuron 92:873-887.

White G (1990) GABAA-receptor-activated current in dorsal root ganglion neurons freshly isolated from adult rats. J Neurophysiol 64:57-63.
Yamamori T, Fukada K, Aebersold R, Korsching S, Fann M-J, Patterson PH (1989) The cholinergic neuronal differentiation factor from heart cells is identical to leukemia inhibitory factor. Science 246:1412-1416.

Yang B, Slonimsky JD, Birren SJ (2002) A rapid switch in sympathetic neurotransmitter release properties mediated by the $\mathrm{p} 75$ receptor. Nat Neurosci 5:539-545.

Yoon B, Lee CJ (2014) GABA as a rising gliotransmitter. Front Neural Circuit 8:141.

Zambetti S, Connors JO, Spitzer NC (2017) Neurotransmitter switching in the adult mouse hippocampus and changes in episodic memory. Soc Neurosci Abstr 43:661.04.

Zhang Z, Chen G, Zhou W, Song A, Xu T, Luo Q, Wang W, Gu X-s, Duan S (2007) Regulated ATP release from astrocytes through lysosome exocytosis. Nat Cell Biol 9:945-953. 